\title{
Rhino Orbital Cerebral Mucormycosis in settings of Covid-19 infection: A Case Series of Thirteen Patients
}

\section{Rajesh Verma ( $\nabla$ drrajeshverma32@yahoo.com)}

King George's Medical University, Lucknow, India Professor, Department of Neurology, King George's Medical University, Lucknow, India

\section{Rajarshi Chakraborty}

Department of Neurology, King George's Medical University, Lucknow, India

\section{Keerthiraj DB}

Department of Neurology, King George's Medical University, Lucknow, India

\section{Kingzang Wangda}

Department of Neurology, King George's Medical University, Lucknow, India

\section{Veerendra Verma}

Department of Otorhinolaryngology \& Head Neck Surgery King George's Medical University, Lucknow, India

\section{Prashant Gupta}

Department of Microbiology, King George's Medical University, Lucknow, India

\section{Research Article}

Keywords: Rhino-Orbital-Cerebral Mucormycosis, immune system, hyperglycaemia, diabetic ketoacidosis, Rhizopus

Posted Date: January 11th, 2022

DOI: https://doi.org/10.21203/rs.3.rs-1240669/v1

License: (ㅇ) (i) This work is licensed under a Creative Commons Attribution 4.0 International License. Read Full License 


\section{Abstract \\ Background}

Rhino-Orbital-Cerebral Mucormycosis (ROCM) is an important infectious disease encountered in huge number in this recent postcovid 19 era. An alteration in defence immune system during covid-19 illness, in the presence of uncontrolled hyperglycaemia has led to the new epidemic of ROCM especially in developing nations like India.

\section{Method}

This case series of thirteen patients illustrates the various clinical presentation, laboratorical parameters, imaging features and outcome of patients of ROCM admitted in a tertiary care hospital in Northern India.

\section{Result}

In our case series, a total of 13 newly diagnosed cases of Rhino-Orbital-Cerebral Mucormycosis were studied. History of covid-19 illness was observed in 7 cases (53.8\%), use of steroid during Covid-19 illness was seen in 5 cases (38.5\%), oxygen therapy was given in 4 cases (30.8\%). Co-morbid state in the form of diabetes mellitus was present in 12 cases (92.3\%) with mean duration 16.69 months with an important finding of 6 cases (46.2\%) having new-onset diabetes; hypertension in present in 3 cases $(23.1 \%)$. Magnetic resonance imaging of paranasal sinuses showed involvement of multiple sinuses in all the 13 cases(100\%), including maxillary and ethmoidal sinuses, with frontal in 12 cases (92.3\%), sphenoidal in 11 cases (84.6\%), symmetric in 9 cases (69.2\%), mastoiditis in 4 cases (30.8\%), maxillary space involvement in 4 cases (30.8\%), palatal involvement in 1 case (7.7\%). Multi-speciality approach treatment was given in the liposomal amphotericin B therapy in all the patients along with thorough endo-nasal debridement done in all cases, transcutaneous retrobulbar amphotericin B in 6 cases (46.2\%) with exenteration done in 7 patients (53.9\%). At 3 months of follow-up, there was substantial clinical improvement in all the cases.

\section{Conclusion}

There should be definite emphasis on high suspicion of mucor clinically for early diagnosis and aggressive management at initial state of diagnosis for better outcome. The need for sustained proper glycemic control during covid 19 era along with judicious use of steroid and public awareness for early symptoms and manifestations of mucor can curb the magnitude of such potentially opportunistic epidemic to a substantial rate. The longer the infection remains undetected, the greater the devastation ROCM can impose, of which blindness is an important hazard.

\section{Introduction}

Rhino-Orbital-Cerebral Mucormycosis is an important infectious disease encountered in huge number in this recent post-covid 19 era. Mucor has been present for long time in medical history, but several epidemics has highlighted its morbid outcome ${ }^{[1]}$. An alteration in immune defence system during covid-19 illness, in the presence of uncontrolled hyperglycaemia has led to the new epidemic of ROCM especially in developing nations like India. The primary reason that appears to be facilitating Mucorales spores to germinate in people with COVID-19 is an ideal environment of low oxygen (hypoxia), high glucose (diabetes, new-onset hyperglycemia, steroidinduced hyperglycemia), acidic medium (metabolic acidosis, diabetic ketoacidosis), high iron levels (increased ferritins) and decreased phagocytic activity of white blood cells (WBC) due to immunosuppression (SARS-CoV-2 mediated, steroid-mediated or background comorbidities) coupled with several other shared risk factors including prolonged hospitalization with or without mechanical ventilators ${ }^{[2]}$. Phycomycosis/zygomycosis was first described in 1885 by Paltauf and later coined as 'Mucormycosis' in 1957 by Baker an American pathologist for an aggressive infection caused by Rhizopus ${ }^{[2,3,4]}$. The Rhizopus Oryzae is most common type and responsible for $90 \%$ of Rhino-orbital-cerebral form ${ }^{[5]}$. The mode of contamination is through the inhalation of fungal spores. India, being the Diabetes capital of world along with second most country affected by covid-19 illness lead to epidemic of ROCM recently ${ }^{[6,7,8,9]}$.There have been multiple but sparse case series globally depicting the clinical profile, laboratorical workup, imaging 
features in ROCM in the past, but during post-covid 19 state esp the second wave, there is a vast increase in ROCM cases throughout Indian population $[10,11,12,13,14,15,16,17,18,19,20,21]$.

The diagnosis of ROCM is confirmed after detection of fungal spore along with correlation of imaging in the background of clinical profile. The 1950 Smith and Krichner criteria for the clinical diagnosis of mucormycosis are still considered to be gold standard and include: ${ }^{[2,22]}$

(i) Black, necrotic turbinate's easily mistaken for dried, crusted blood,

(ii) Blood-tinged nasal discharge and facial pain, both on the same side,

(iii) Soft peri-orbital or peri-nasal swelling with discoloration and induration,

(iv) Ptosis of the eyelid, proptosis of the eyeball and complete ophthalmoplegia and,

(v) Multiple cranial nerve palsies unrelated to documented lesions.

The treatment of such aggressive disease is multidisciplinary efforts. Antifungal like intravenous amphotericin B or isuvaconazole, followed by oral posaconazole are the main medical therapy, with good debridement of local nasal tissue debris, transcutaneous retrobulbar amphotericin $B$ injections, timely exenteration being the corner-stone of treatment ${ }^{[23,24,25,26,27,28,29]}$. Sustained euglycaemia yields better results in outcome ${ }^{[30,31,32,33,33,34,35,36,37]}$

\section{Objective}

This case series of 13 patients illustrates the various clinical presentation, laboratorical parameters, imaging features and outcome of patients of ROCM admitted in a tertiary care hospital in Northern India.

\section{Method}

We studied the demographics, clinical presentation, laboratorical profile, imaging features and clinical outcome in 13 patients of newly diagnosed cases of Rhino-Orbital-Cerebral Mucormycosis. All the patients were thoroughly evaluated, treated as per standard protocols and staging and followed-up at 3 months from being discharged. The consent were obtained from all patients or their relatives/local guardians.

\section{Result}

In our case series, a total of 13 newly diagnosed cases of Rhino-Orbital-Cerebral Mucormycosis were studied with the youngest being 17 years old and eldest being 75 years age with a mean age of 47.69 years. The male: female ratio observed was 0.625 (5:8). History of covid-19 illness was observed in 7 cases (53.8\%), use of steroid during Covid-19 illness was seen in 5 cases (38.5\%), oxygen therapy was given in 4 cases (30.8\%). Co-morbid state in the form of diabetes mellitus was present in 12 cases (92.3\%) with mean duration 16.69 months with an important finding of 6 cases (46.2\%) having new-onset diabetes; hypertension in present in 3 cases (23.1\%). The most common presentation was nasal discharge, headache and swelling of eye which was seen in all 13 patients (100\%), followed by dimness of vision in 9 cases (69.2\%), fever seen in 8 cases (61.5\%), gradual onset loss of vision (blindness) in 7 cases (53.9\%), toothache and facial numbness in 7 cases (53.9\%), facial weakness in 6 cases (46.2\%) with cough in 3 patients $(20.1 \%)$. Of due note was the duration of illness and presentation to hospital set-up which was 31.54 days on an average. Among the important signs, sinusitis was observed in all 13 cases (100\%) with involvement of maxillary and ethmoidal in all cases and symmetricity observed in 9 cases (69.2\%), complete ophthalmoplegia in 8 cases (61.5\%), perception of light negative in 6 cases (46.2\%), lower motor neuron facial palsy in in 6 cases (46.2\%), fundus abnormality in 4 cases (30.8\%), Relative afferent pupillary defect (RAPD) in 2 cases (15.4\%), palatal defect with pus discharge in 1 case $(7.7 \%)$. The laboratorical workup showed anemia in 8 cases $(61.5 \%)$, raised $C$ reactive protein in all 13 cases $(100 \%)$ with a mean of 48.23 units, procalcitonin $<0.05$ in all cases, hyponatremia in 12 cases (92.3\%), hypokalemia in 11 cases (84.6\%), hypocalcemia in 13 cases (100\%), hyperglycemia in 12 cases (53.8\%), hyperferritinemia in 8 cases (61.5\%), elevated lactate dehydrogenase in 4 cases (30.8\%), transient renal injury in 1 case $(7.7 \%)$, while tranaminitis or hyperbilirubinemia was not observed. Fungal detection in nasal scrapping via $\mathrm{KOH}$ mount was positive for all the cases ( Figure-1). The imaging profile under ROCM protocol had clinical correlation and magnetic resonance imaging changes were observed in all cases (100\%) in paranasal sinuses and orbit with involvement of brain was detected in imaging in 9 
cases (69.2\%). Magnetic resonance imaging of paranasal sinuses showed involvement of multiple sinuses in all the 13 cases(100\%), including maxillary and ethmoidal sinuses, with frontal in 12 cases (92.3\%), sphenoidal in 11 cases (84.6\%), symmetric in 9 cases (69.2\%), mastoiditis in 4 cases (30.8\%), maxillary space involvement in 4 cases (30.8\%), palatal involvement in 1 case (7.7\%)( Figure2). MRI imaging of orbit showed ocular involvement in all the 13 cases $(100 \%)$ with bony involvement seen in all the 13 cases $(100 \%)$, extra-ocular muscles involvement in 12 cases (92.3\%), optic nerve involvement in 7 cases (53.9\%), and orbital apex involvement in 6 cases (46.2\%), with one case of symmetric involvement of both eyes (7.7\%)(Figure-2). Mri of brain showed involvement in 9 cases (69.2\%), mostly temporal dural enhancement seen in 8 cases (61.5\%), erosion of cribriform plate in 5 cases (38.5\%), cavernous sinus involvement in 4 cases (30.8\%), loss of internal carotid artery flow void in 3 cases (23.1\%), infarct in 1 case (7.7\%) and cerebritis in 1 case $(7.7 \%)$ without any case showing symmetricity (Figure-3). Majority of cases were suffering from stage 4 of ROCM (total 9 cases) and rest 4 were having stage 3 ROCM. Multi-speciality approach treatment was given in the liposomal amphotericin B therapy in all the patients along with thorough endo-nasal debridement done in all cases( Figure-4), transcutaneous retrobulbar amphotericin B in 6 cases (46.2\%) with exenteration done in 7 patients (53.9\%). The mean duration of hospital stay was 36.69 days with no mortality. At 3 months of follow-up, there was substantial clinical improvement in all the cases in the clinical parameters of headache ( 2 cases), swelling of eye (3 cases), nasal discharge (one case), fever (none), residual facial weakness (3 cases), but numbness of face persisted in all the previous 7 cases to some extent, with no new symptoms during follow-up. Radiological de-staging of ROCM was observed in all the cases at follow-up.

\section{Discussion}

This case series showed a slightly earlier mean age of presentation of 47.69 years as compared to other studies showing above 55 years $^{[6,13,21,34,34,36,37]}$. The sex ratio is showing female dominance as compared to male dominance in other case series ${ }^{[6,13,21]}$. The presence of diabetes mellitus is $92.3 \%$ which correlates with other case series globally. ${ }^{21}$

The detection of new onset diabetes in our series is $46.2 \%$ which was higher than previously noted in reports. The phenomena of naïve hyperglycaemic status along with covid illness might trigger to hypothesis of immune dysregulation in early diabetes precipitating opportunistic infectious diseases like ROCM. Sinusitis along with ocular involvement in some form was evident in all the cases at presentation to admission. The mean duration of illness was 31.54 days with earliest of 15 days and maximum of 45 days was observed which is quite late than other studies ${ }^{[13]}$. Blindness was seen in seven cases (53.9\%), orbital apex syndrome seen in 6 cases (46.2\%), complete ophthalmoplegia seen in 8 cases (61.5\%): a higher involvement basically is being observed as compared with other studies ${ }^{[6,13,21]}$.

Multiple paranasal sinuses were involved and majority showed the involvement of maxillary and ethmoidal sinuses, this was also seen in some other studies. A greater number of cases showed nervous system involvement $69.2 \%$, which is higher than other case series Hence most of the patients were seen in stage 4 with higher neurological manifestations $[6,13,21,28]$. The reason probably was due to late presentation of patients, by the time the disease has already progressed. Debridement of endonasal necrotic tissues were successfully done with regular follow-up in all cases. The use of transcutaneous retrobulbar amphotericin B was done in 7 cases of appropriate staging helped regression of further intraocular damage. The rate of exenteration was $53.9 \%$ which was quite higher due to increased cases of blindness at presentation ${ }^{[13]}$. Aggressive surgico-medical management with strict glycaemic control lead to better outcome.

\section{Conclusion}

Rhino-orbital-cerebral mucormycosis is a potentially treatable aggressive fungal disease of sino-ocular-neural system. A high degree of suspicion for mucor in all the cases of rhino-sinusitis along with aggressive management at disease onset itself are the keys to early prevention of such destructible course in ROCM illness. Proper glycemic control is advocated amidst the covid-19 era along with judicious use of steroid whenever indicated as there are increased cases of ROCM with newly detected diabetes mellitus. Multidisciplinary team approach will result in better outcome. There is need for further awareness among public as well as primary-care physicians regarding early possible symptoms of ROCM and necessity of early antifungal initiation to curb the magnitude of such potentially treatable opportunistic epidemic to a substantial rate. The longer the infection remains undetected, the greater the devastation ROCM can impose, of which blindness is an important hazard. The delay in diagnosis and proper treatment directly affects outcome in ROCM. 


\section{Declarations}

Ethics: Patients were consented and institutional ethical committee approval obtained.

Competing Interests: The authors declare no competing interest.

\section{References}

1. Vaughan C, Bartolo A, Vallabh N, Leong SC. A meta-analysis of survival factors in rhino-orbital-cerebral mucormycosis-has anything changed in the past 20 years? Clin Otolaryngol. 2018;43(6):1454-1464.

2. Singh A.K., Singh R., Joshi S.R., Misra A., Mucormycosis in COVID-19: A systematic review of cases reported worldwide and in India. Diabetes \{\&\}amp; Metabolic Syndrome. 2021; 15 (4): 102146.

3. Paltauf A. Mycosis mucorina. Virchows Arch Pathol Anat Physiol Klin Med 1885;102:543e64.

4. Baker RD. Mucormycosis-a new disease? J Am Med Assoc 1957;163:805e8.

5. Sugar AM. In: Mandell GL, Bennett JE, Dolin R, editors. Mandell, Douglas, and Bennett's principles and practice of infectious diseases. fifth ed. New York, USA: Churchill Livingstone; 2000.

6. Dave TV, Nair AG, Hegde R, Vithalani N, Desai S, Adulkar N, Kamal S, Mittal R, Bradoo RA. Clinical presentations, management and outcomes of rhino-orbital-cerebral mucormycosis (ROCM) following COVID-19: a multi-centric study. Ophthalmic plastic and reconstructive surgery. 2021 Sep;37(5):488.

7. Diwakar J, Samaddar A, Konar SK, Bhat MD, Manuel E, HB V, BN N, Parveen A, Hajira SN, Srinivas D. First Report of COVID-19associated Rhino-Orbito-Cerebral Mucormycosis in Pediatric patients with Type 1 Diabetes Mellitus.

8. Bhattacharyya A, Sarma P, Sharma DJ, Das KK, Kaur H, Prajapat M, Kumar S, Bansal S, Prakash A, Avti P, Thota P. Rhino-orbitalcerebral-mucormycosis in COVID-19: A systematic review. Indian Journal of Pharmacology. 2021 Jul;53(4):317.

9. Singh P, Arora S, Mittal N, Singh A, Verma R, Sharma S, Agrawal NK, Goyal S. Diabetes and rhino-orbito-cerebral mucormycosis-A deadly duo. Journal of Diabetes \& Metabolic Disorders. 2021 Jan 21:1-7.

10. Singh G, Vishnu VY. Neurological manifestations of rhino-oculo-cerebral mucormycosis in the COVID-19 era. Nature Reviews Neurology. 2021 Sep 3:1-2.

11. Prakash H, Chakrabarti A. Epidemiology of mucormycosis in India. Microorganisms. 2021 Mar;9(3):523.

12. Rawat A, Chakrawarty J, Jain S, Newaskar V, Jain S. Mucormycosis in Post Covid Patients: A Case Series. International Journal. 2021 Sep;4(5):1166.

13. Gandhi A, Narula A, Chandra S, Agarwal D, Mehta A, Arora S, Nayak S, Capoor MR. Battling the Emerging Epidemic of RhinoOrbital-Cerebral Mucormycosis (ROCM) in COVID-19 Pandemic: A Prospective Interventional Study.

14. Singh H, Dua S, Goel A, Dhar A, Bhadauria V, Garg A, Katyar V, Sharma S, Shukla A. Rhino-orbital-cerebral mucormycosis in times of COVID-19: A neurosurgical experience. Surgical Neurology International. 2021;12.

15. Gambhir RS, Aggarwal A, Bhardwaj A, Kaur A, Sohi RK, Mehta S. COVID-19 and mucormycosis (black fungus): an epidemic within the pandemic. Rocz Panstw Zakl Hig. 2021 Jan 1;72(3):1-6.

16. Pai V, Sansi R, Kharche R, Bandili SC, Pai B. Rhino-orbito-cerebral Mucormycosis: Pictorial Review. Insights into imaging. 2021 Dec;12(1):1-7.

17. Pal R, Singh B, Bhadada SK, Banerjee M, Bhogal RS, Hage N, Kumar A. COVID-19-associated mucormycosis: An updated systematic review of literature. Mycoses. 2021 Jun 16.

18. Pal P, Chatterjee N, Ghosh S, Ray BK, Mukhopadhyay P, Bhunia K, Srivastava SR, Adhikari S, Barman D, Banerjee B, Mukhopadhyay M. COVID Associated Mucormycosis: A Study on the Spectrum of Clinical, Biochemical and Radiological Findings in A Series of Ten Patients. The Journal of the Association of Physicians of India. 2021 Oct 1;69(10):11-2.

19. Laghimsetty S, Sujatha Y, Muddam VR. Rhino-orbital-cerebral mucormycosis: A clinical guide for ophthalmologists. Journal of Ophthalmology Clinics \& Research. 2021 Jan 1;1(1):16.

20. Balwan WK. Epidemiology of Mucormycosis in India: A Notifiable Disease. Saudi J Pathol Microbiol. 2021;6(6):187-91.

21. Arora R, Goel R, Khanam S, Kumar S, Shah S, Singh S, Chhabra M, Meher R, Khurana N, Sagar T, Kumar S. Rhino-Orbito-CerebralMucormycosis During the COVID-19 Second Wave in 2021-A Preliminary Report from a Single Hospital. Clinical Ophthalmology

Page 5/11 
(Auckland, NZ). 2021;15:3505.

22. Smith HW, Kirchner JA. Cerebral mucor-mycosis: a report of 3 cases. Arch Otolaryngol 1950;68:715e26.

23. Chegini Z, Didehdar M, Khoshbayan A, Rajaeih S, Salehi M, Shariati A. Epidemiology, clinical features, diagnosis and treatment of cerebral mucormycosis in diabetic patients: a systematic review of case reports and case series. Mycoses. 2020 Dec;63(12):1264-82.

24. Abdolalizadeh P, Kashkouli MB, Khademi B, Karimi N, Hamami P, Es' haghi A. Diabetic versus non-diabetic rhino-orbito-cerebral mucormycosis. Mycoses. 2020 Jun;63(6):573-8.

25. Behera M, Das S. Type 2 Diabetic Presenting as a Case of Rhino-Orbital-Cerebral Mucormycosis. Diabetes Clinical Case Series-1. 2016 Feb 12;1:31.

26. Manesh A, John AO, Mathew B, Varghese L, Rupa V, Zachariah A, Varghese GM. Posaconazole: an emerging therapeutic option for invasive rhino-orbito-cerebral mucormycosis. Mycoses. 2016 Dec;59(12):765-72.

27. Rabiei MM, Zali A, Roodsari SR, Arab-Mazar Z, Lotfali E. Fungal Central Nervous System Infections in Patients With COVID-19. International Clinical Neuroscience Journal. 2021;8(4):154-6.

28. Kashkouli MB, Abdolalizadeh P, Oghazian M, Hadi Y, Karimi N, Ghazizadeh M. Outcomes and factors affecting them in patients with rhino-orbito-cerebral mucormycosis. British Journal of Ophthalmology. 2019 Oct 1;103(10):1460-5.

29. DiBartolo MA, Kelley PS. Rhino-orbital-cerebral mucormycosis (ROCM): a comprehensive case review. Aviation, space, and environmental medicine. 2011 Sep 1;82(9):913-6.

30. Beiglboeck FM, Theofilou NE, Fuchs MD, Wiesli MG, Leiggener C, Igelbrink S, Augello M. Managing mucormycosis in diabetic patients: A case report with critical review of the literature. Oral Diseases. 2021 Feb 14.

31. Salehi M, Shahi F, Rizvi FS, Ghaderkhani S, Zainaldain H, Khodavaisy S, Jamali-Moghaddam SR, Manshadi SA, Rezahosseini O. Combination antifungal therapy without craniotomy in an immunocompromised patient with rhino-orbito-cerebral mucormycosis: A case report. Caspian Journal of Internal Medicine. 2020;11(2):227.

32. Alloush TK, Mansour O, Alloush AT, Roushdy T, Hamid E, El-Shamy M, Shokri HM. Rhino-orbito-cerebral mucormycosis during the COVID-19 third wave in 2021: an Egyptian preliminary report from a single tertiary hospital. Neurological Sciences. 2021 Nov $17: 1-1$.

33. Taha R, Almteri T, Bahabri N, Almoallim H. Rhino-orbito-cerebral mucormycosis in immunocompetent young patient: case Report. Clin Med Rev Case Rep. 2018;5:207.

34. Pakdel F, Ahmadikia K, Salehi M, et al. Mucormycosis in patients with COVID-19: a cross-sectional descriptive multicentre study from Iran. Mycoses. 2021. doi:10.1111/myc.133346.

35. Sen M, Honavar SG, Bansal R, et al. Epidemiology, clinical profile, management, and outcome of COVID-19-associated rhinoorbital- cerebral mucormycosis in 2826 patients in India - collaborative OPAI-IJO Study on Mucormycosis in COVID-19 (COSMIC), report 1. Indian J Ophthalmol. 2021;69(7):1670-1692. doi:10.4103/ijo. IJO_1565_217.

36. Ramaswami A, Sahu AK, Kumar A, et al. COVID-19 associated mucormycosis presenting to the emergency department - an Observational Study of 70 patients. QJM. 2021. doi:10.1093/qjmed/ hcab1908. Honavar SG.

37. Hoenigl M, Seidel D, Carvalho A, et al. The emergence of COVID-19 associated mucormycosis: analysis of cases from 18 countries. SSRN. 2021. doi:10.2139/ssrn.384458716

\section{Tables}

TABLE 1 : CLINICOLABORATORICAL PROFILE OF ROCM PATIENTS 


\begin{tabular}{|c|c|c|c|c|c|c|c|c|c|c|c|c|c|c|}
\hline & $\begin{array}{l}\text { PT } \\
1\end{array}$ & 2 & 3 & 4 & 5 & 6 & 7 & 8 & 9 & 10 & 11 & 12 & 13 & TOTAL \\
\hline AGE & 63 & 75 & 35 & 56 & 46 & 58 & 50 & 45 & 42 & 17 & 45 & 40 & 48 & 47.69 Mean \\
\hline SEX (M:F) & M & $\mathrm{F}$ & $\mathrm{F}$ & $\mathrm{F}$ & $\mathrm{F}$ & $\mathrm{F}$ & M & $\mathrm{M}$ & $\mathrm{F}$ & M & $\mathrm{F}$ & $\mathrm{F}$ & M & $5: 8(0.625)$ \\
\hline COVID + STATUS & - & + & + & + & - & + & - & - & + & + & + & - & - & $7 / 13(53.8 \%)$ \\
\hline STEROID USE & - & + & + & - & - & + & - & - & - & + & + & - & - & $5 / 13(38.5 \%)$ \\
\hline OXYGEN USE & - & + & + & - & - & + & - & - & - & - & + & - & - & 4/13(30.8\%) \\
\hline DIABETES MELLITUS & + & + & + & + & + & + & + & + & + & - & + & + & + & $12 / 13(92.3 \%)$ \\
\hline DURATION OF DM (months) & 12 & 1 & 1 & 1 & 1 & 48 & 2 & 6 & 24 & - & 48 & 72 & 1 & 16.69 month \\
\hline HYPERTENSION & - & + & - & - & - & - & + & - & - & - & + & - & - & 3/13(23.1\%) \\
\hline FEVER & - & + & + & + & + & + & + & - & - & + & + & - & - & $8 / 13(61.5 \%)$ \\
\hline COUGH & - & + & + & - & - & - & - & - & - & - & + & - & - & 3/13(20.1\%) \\
\hline $\begin{array}{l}\text { DURATION OF ILLNESS } \\
\text { (days) }\end{array}$ & 30 & 45 & 45 & 45 & 45 & 40 & 30 & 20 & 30 & 15 & 20 & 20 & 25 & 31.54 days \\
\hline NASAL DISCHARGE & + & + & + & + & + & + & + & + & + & + & + & + & + & $13 / 13(100 \%)$ \\
\hline HEADACHE & + & + & + & + & + & + & + & + & + & + & + & + & + & $13 / 13(100 \%)$ \\
\hline EYE SWELLING & + & + & + & + & + & + & + & + & + & + & + & + & + & 13/13(100\%) \\
\hline DIMNSESS VISION & - & + & - & - & + & + & + & + & + & + & - & + & + & 9/13(69.2\%) \\
\hline BLINDNESS & - & + & - & - & - & - & + & + & + & + & - & + & + & $7 / 13(53.9 \%)$ \\
\hline TEETH PAIN & + & - & - & - & + & + & + & - & - & - & + & + & + & $7 / 13(53.9 \%)$ \\
\hline FACIAL WEAKNESS & - & + & - & + & + & + & - & - & + & - & - & + & - & $6 / 13(46.2 \%)$ \\
\hline FACIAL NUMBNESS & - & + & - & + & + & + & + & - & - & - & + & - & + & $7 / 13(53.8 \%)$ \\
\hline RAPD & - & - & - & - & - & - & - & + & - & + & - & - & - & $2 / 13(15.4 \%)$ \\
\hline $\begin{array}{l}\text { COMPLETE } \\
\text { OPHTHALMOPLEGIA }\end{array}$ & - & + & - & - & + & + & + & + & + & + & - & + & - & $8 / 13(61.5 \%)$ \\
\hline FUNDUS ABNORMALITY & - & + & - & - & - & - & + & - & + & - & - & + & - & $4 / 13(30.8 \%)$ \\
\hline ANEMIA & + & + & + & + & - & + & + & - & + & - & - & + & - & $8 / 13(61.5 \%)$ \\
\hline CRP & 66 & 51 & 106 & 102 & 65 & 74 & 23 & 17 & 57 & 20 & 51 & 18 & 42 & 48.23 \\
\hline HYPONATREMIA & + & + & + & + & + & + & + & + & - & + & + & + & + & $12 / 13(92.3 \%)$ \\
\hline HYPOKALEMIA & + & + & + & + & + & - & - & + & + & + & + & + & + & $11 / 13(84.6 \%)$ \\
\hline HYPOCALCEMIA & + & + & + & + & + & + & + & + & - & + & + & + & + & 13/13(100\%) \\
\hline RENAL INJURY & - & + & - & - & - & - & - & - & - & - & - & - & - & $1 / 13(7.7 \%)$ \\
\hline TRANSAMININTIS & - & - & - & - & - & - & - & - & - & - & - & - & - & 0 \\
\hline ELEVATED LDH & - & + & - & - & - & + & - & - & + & + & - & - & - & $4 / 13(30.8 \%)$ \\
\hline HYPERGLYCEMIA & + & + & + & + & + & + & + & + & + & - & + & + & + & $12 / 13(92.3 \%)$ \\
\hline HYPERFERRITINEMIA & + & + & + & + & - & + & - & + & - & - & - & + & + & $8 / 13(61.5 \%)$ \\
\hline MRI PNS CHANGES & + & + & + & + & + & + & + & + & + & + & + & + & + & 13/13(100\%) \\
\hline MRI ORBIT CHANGES & + & + & + & + & + & + & + & + & + & + & + & + & + & 13/13(100\%) \\
\hline
\end{tabular}




\begin{tabular}{|c|c|c|c|c|c|c|c|c|c|c|c|c|c|c|}
\hline MRI BRAIN CHANGES & - & + & - & + & + & + & + & + & - & + & - & + & + & $9 / 13(69.2 \%)$ \\
\hline STAGE OF ROCM & 3 & 4 & 3 & 4 & 4 & 4 & 4 & 4 & 3 & 4 & 3 & 4 & 4 & 4 IN 9/13 \\
\hline $\mathrm{KOH}+$ & + & + & + & + & + & + & + & + & + & + & + & + & + & $13 / 13(100 \%)$ \\
\hline SYSTEMIC AMPHOTERICIN & + & + & + & + & + & + & + & + & $\mathrm{H}$ & + & + & + & + & $12 / 13(92.3 \%)$ \\
\hline $\begin{array}{l}\text { RETROBULBAR } \\
\text { AMPHOTERICIN }\end{array}$ & + & - & + & + & + & + & - & - & - & - & + & - & - & $6 / 13(46.2 \%)$ \\
\hline EXENTERATION & - & + & - & - & - & - & + & + & + & + & - & + & + & $7 / 13(53.9 \%)$ \\
\hline ENT DEBRIDEMENT & + & + & + & + & + & + & + & + & + & + & + & + & + & $13 / 13(100 \%)$ \\
\hline DURATION OF STAY (days) & 28 & 32 & 33 & 30 & 40 & 40 & 23 & 33 & 43 & 40 & 43 & 52 & 40 & 36.69 days \\
\hline FOLLOW-UP & 1 & I & I & I & I & I & I & I & I & I & I & I & I & \\
\hline
\end{tabular}

I-Improved

TABLE 2 : MRI PROFILE OF ROCM PATIENTS 


\begin{tabular}{|c|c|c|c|c|c|c|c|c|c|c|c|c|c|c|}
\hline & PT1 & PT2 & PT3 & PT4 & PT5 & PT6 & PT7 & PT8 & PT9 & PT10 & PT11 & PT12 & PT13 & TOTAL \\
\hline MRI BRAIN:- & & & & & & & & & \multicolumn{6}{|c|}{$9 / 13$} \\
\hline $\begin{array}{l}\text { DURAL } \\
\text { ENHANCEMENT }\end{array}$ & - & B & - & - & $\mathrm{L}$ & L & $\mathrm{R}$ & $\mathrm{R}$ & - & $\mathrm{R}$ & - & $\mathrm{L}$ & L & 8 \\
\hline CEREBRITIS & - & - & - & - & - & - & - & - & - & $\mathrm{R}$ & - & - & - & 1 \\
\hline ABSCESS & - & - & - & - & - & - & - & - & & - & - & - & - & 0 \\
\hline $\begin{array}{l}\text { CAVERNOUS } \\
\text { SINUS } \\
\text { INVOLVEMENT }\end{array}$ & - & $\mathrm{R}$ & - & L & - & L & $\mathrm{R}$ & - & - & - & - & - & - & 4 \\
\hline $\begin{array}{l}\text { ICA LOSS OF } \\
\text { FLOW VOIDS }\end{array}$ & - & $\mathrm{R}$ & - & - & - & L & $\mathrm{R}$ & - & - & - & - & - & - & 3 \\
\hline INFARCT & - & - & - & - & - & - & $\mathrm{R}$ & - & - & - & - & - & - & 1 \\
\hline HEMORRHAGE & - & - & - & - & - & - & - & - & - & - & - & - & - & 0 \\
\hline $\begin{array}{l}\text { CRIBRIFORM } \\
\text { PLATE } \\
\text { EROSION }\end{array}$ & - & + & + & - & - & - & - & + & - & - & + & + & - & 5 \\
\hline SYMMETRICITY & - & - & - & - & - & & - & - & - & - & - & - & - & 0 \\
\hline MRI ORBIT:- & & & & & & & & & \multicolumn{6}{|c|}{$13 / 13$} \\
\hline BONY EROSION & $\mathrm{R}$ & B & L & L & $\mathrm{L}$ & L & $\mathrm{R}$ & $\mathrm{R}$ & $\mathrm{R}$ & $\mathrm{R}$ & L & $\mathrm{L}$ & L & 13 \\
\hline $\begin{array}{l}\text { INVOLVEMENT } \\
\text { OF EXTRA- } \\
\text { OCULAR } \\
\text { MUSCLES }\end{array}$ & $\mathrm{R}$ & B & L & - & $L$ & L & $\mathrm{R}$ & $\mathrm{R}$ & $\mathrm{R}$ & $\mathrm{R}$ & L & $\mathrm{L}$ & L & 12 \\
\hline $\begin{array}{l}\text { OPTIC NERVE } \\
\text { INVOLVEMENT }\end{array}$ & - & $\mathrm{R}$ & - & - & - & - & $\mathrm{R}$ & $\mathrm{R}$ & $\mathrm{R}$ & $\mathrm{R}$ & - & $\mathrm{L}$ & L & 7 \\
\hline $\begin{array}{l}\text { ORBITAL APEX } \\
\text { SYNDROME }\end{array}$ & - & $\mathrm{R}$ & - & - & - & - & $\mathrm{R}$ & $\mathrm{R}$ & $\mathrm{R}$ & $\mathrm{R}$ & - & $\mathrm{L}$ & - & 6 \\
\hline SYMMETRICITY & - & + & - & - & - & - & - & - & - & - & - & - & - & 1 \\
\hline MRI PNS:- & & & & & & & & & \multicolumn{6}{|c|}{$13 / 13$} \\
\hline $\begin{array}{l}\text { MAXILLARY } \\
\text { SINUSITIS }\end{array}$ & B & B & B & B & $\mathrm{L}$ & B & B & B & $\mathrm{R}$ & $\mathrm{R}$ & L & $\mathrm{L}$ & L & 13 \\
\hline $\begin{array}{l}\text { ETHMOIDAL } \\
\text { SINUSITIS }\end{array}$ & B & B & L & L & $\mathrm{L}$ & B & B & B & $\mathrm{R}$ & $\mathrm{R}$ & B & $\mathrm{L}$ & B & 13 \\
\hline $\begin{array}{l}\text { FRONTAL } \\
\text { SINUSITIS }\end{array}$ & $\mathrm{R}$ & B & - & L & $\mathrm{L}$ & L & L & $\mathrm{R}$ & $\mathrm{R}$ & $\mathrm{R}$ & L & $\mathrm{L}$ & $\mathrm{R}$ & 12 \\
\hline $\begin{array}{l}\text { SPHENOIDAL } \\
\text { SINUSITIS }\end{array}$ & $\mathrm{R}$ & B & - & L & $\mathrm{L}$ & B & B & B & $\mathrm{R}$ & $\mathrm{R}$ & L & $\mathrm{L}$ & - & 11 \\
\hline $\begin{array}{l}\text { MULTIPLE } \\
\text { SINUSES }\end{array}$ & + & + & + & + & + & + & + & + & + & + & + & + & + & 13 \\
\hline \multirow{3}{*}{$\begin{array}{l}\text { BILATERAL } \\
\text { SINUSES }\end{array}$} & ME & ME & M & M & - & ME & $\mathrm{ME}$ & $\mathrm{ME}$ & - & - & $E$ & - & E & 9 \\
\hline & $S$ & $S$ & & & & $S$ & S & $S$ & & & & & & \\
\hline & & $F$ & & & & & & & & & & & & \\
\hline $\begin{array}{l}\text { MASTICATORY } \\
\text { SPACES }\end{array}$ & + & - & - & - & + & + & + & - & - & - & - & + & + & 6 \\
\hline MASTOIDITIS & - & B & - & - & - & L & - & - & - & - & $\mathrm{R}$ & $\mathrm{L}$ & & 4 \\
\hline PALATAL & - & - & - & - & - & - & - & - & - & - & - & - & L & 1 \\
\hline
\end{tabular}


B - bilateral, L - left, $R$ - right

Sinuses : M - maxillary, E-Ethmoid, S- sphenoid, F- frontal

\section{Figures}

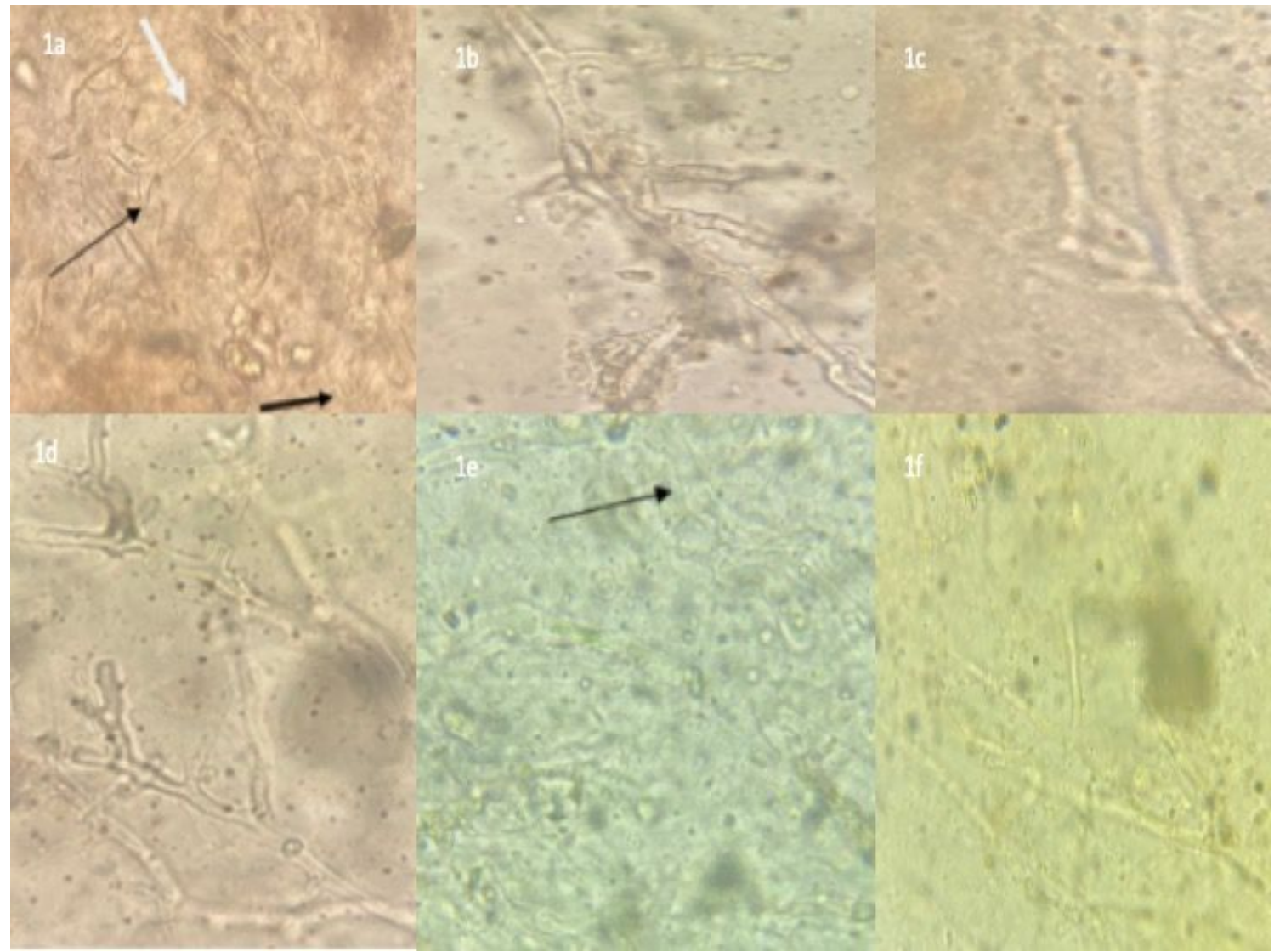

\section{Figure 1}

20\% KOH Mount Microscopic Image Showing:1a.Partially septate (blue arrow) right angle branching (black thick arrow), ribbon like folding (black thin arrow), 1b.Broad aseptate hyphae, 1c.Broad aseptate right angle branching hyphae 1d.Broad, partially septate, right angle branching hyphae, 1e.Aseptate, broad fungal hyphae(Black arrow), 1f.Aseptate hyphae

\section{Figure 2}

Imaging features of ROCM . (A,B) Black turbinate sign : an early sentinel sign of Ischemia and non-enhancement of turbinates in MRI scan, (C) CT axial image shows subtle increased density in intraconal fat in the right orbit, representing early inflammatory process, $(D, E)$ showing orbital invasion and severe compromise of right nasal cavity and ethmoid cells in T1 fat contrast of MRI,( F) left sided Sphenoidoethmoiditis $(G)$ left maxillary sinusitis with masticatory space inflammation, $(H)$ left sphenoidal sinusitis with temporal dural enhancement, (I)loss of ICA flow void, 

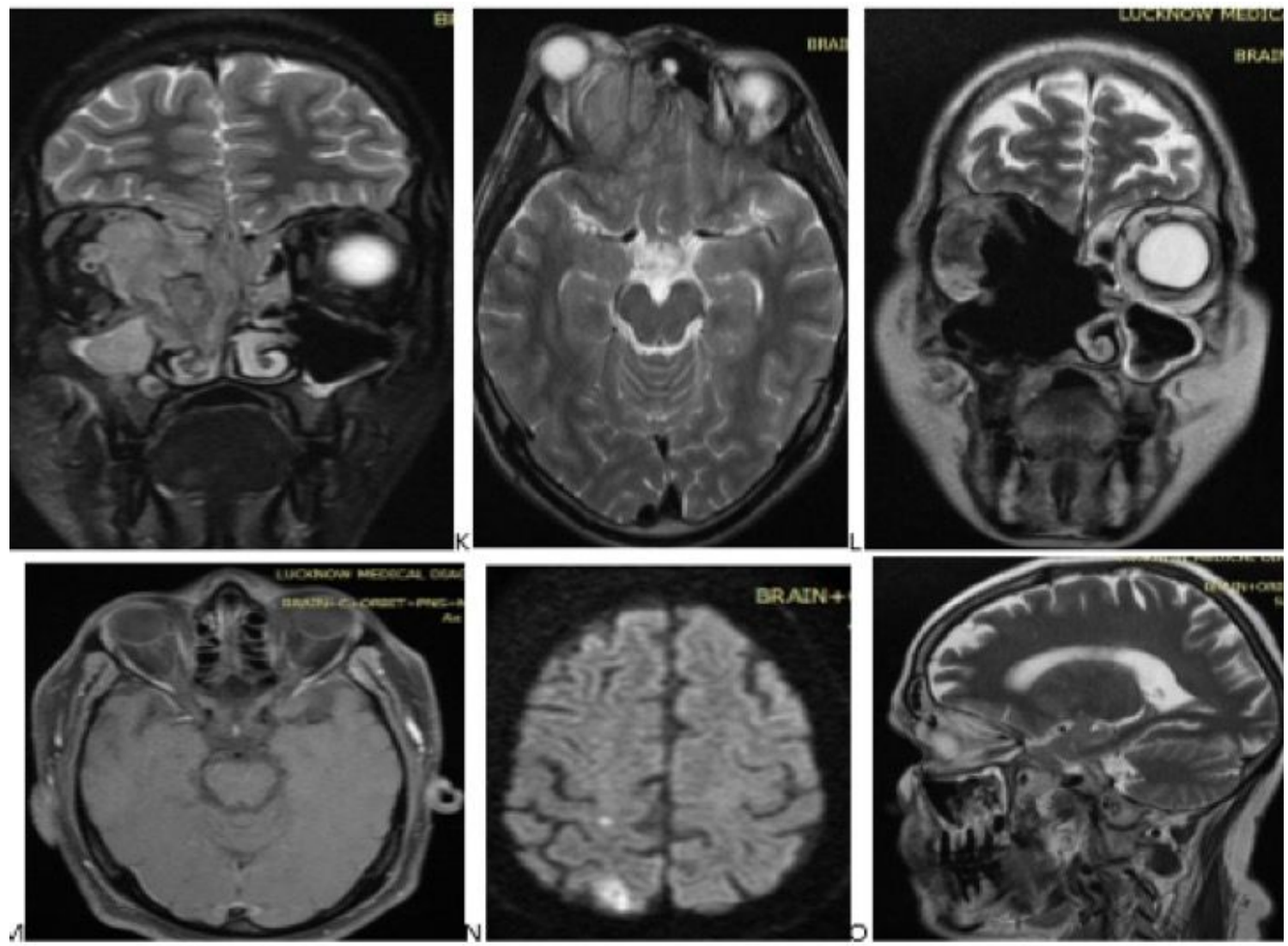

\section{Figure 3}

Imaging features of ROCM : $(\mathrm{J})$ Inflammation of orbital tissues, right maxillary and nasal cavity, $(\mathrm{K})$ R eye proptosis with orbital infiltration, $(L)$ R eye exenterating with extensive sinus debridement state,(M) Bilateral temporal dural enhancement, $(N)$ Infarct, (0)Fronto-maxillary sinusitis

\section{Figure 4}

Nasal Endoscopic Imaging revealed eschar over middle turbinate and slough over septum and medial wall of maxillary sinus $2 \mathrm{a}$, middle turbinate $2 \mathrm{~b}$, nasal septum $2 \mathrm{c}$. 